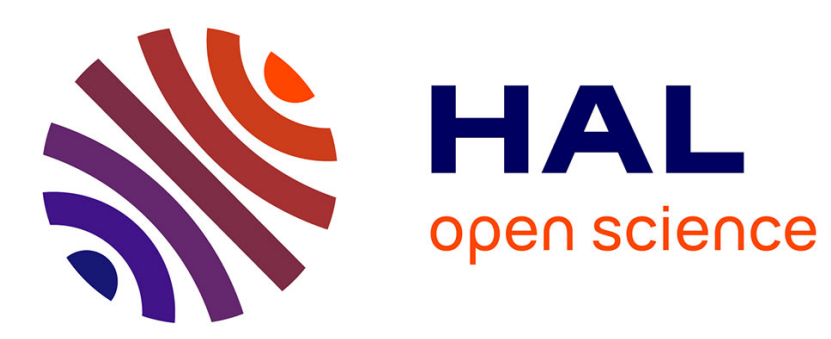

\title{
Ten year recurrence time between two major earthquakes affecting the same fault segment
}

Martin Vallée, Claudio Satriano

\section{To cite this version:}

Martin Vallée, Claudio Satriano. Ten year recurrence time between two major earthquakes affecting the same fault segment. Geophysical Research Letters, 2014, 41, pp.2312-2318. 10.1002/2014GL059465 . insu-03581134

\section{HAL Id: insu-03581134 \\ https://hal-insu.archives-ouvertes.fr/insu-03581134}

Submitted on 19 Feb 2022

HAL is a multi-disciplinary open access archive for the deposit and dissemination of scientific research documents, whether they are published or not. The documents may come from teaching and research institutions in France or abroad, or from public or private research centers.
L'archive ouverte pluridisciplinaire HAL, est destinée au dépôt et à la diffusion de documents scientifiques de niveau recherche, publiés ou non, émanant des établissements d'enseignement et de recherche français ou étrangers, des laboratoires publics ou privés. 


\section{Geophysical Research Letters}

\author{
RESEARCH LETTER \\ 10.1002/2014GL059465 \\ Key Points: \\ - Two major earthquakes occurred \\ within 10 years on the same \\ fault segment \\ - Recurrence time of major earth- \\ quakes can be very irregular \\ - Stress drop of a recent earthquake \\ can be overcome by dynamic \\ seismic stresses
}

\author{
Supporting Information: \\ - Readme \\ - Figure S1 \\ - Figure S2 \\ - Figure S3 \\ - Figure S4 \\ - Figure S5 \\ - Figure S6 \\ - Figure S7 \\ - Text S1 \\ - Text S2 \\ - Text S3
}

Correspondence to:

M. Vallée,

vallee@ipgp.fr

Citation:

Vallée, M., and C. Satriano (2014) Ten year recurrence time between two major earthquakes affecting the same fault segment, Geophys. Res. Lett., 41, 2312-2318, doi:10.1002/2014GL059465.

Received 1 FEB 2014 Accepted 13 MAR 2014 Accepted article online 15 MAR 2014 Published online 3 APR 2014

\section{Ten year recurrence time between two major earthquakes affecting the same fault segment}

\author{
Martin Vallée ${ }^{1}$ and Claudio Satriano ${ }^{1}$ \\ ${ }^{1}$ Institut de Physique du Globe de Paris, Sorbonne Paris Cité, Université Paris Diderot, UMR 7154 CNRS, Paris, France
}

\section{Introduction}

In simple models of stress accumulation and frictional strength of seismic faults, earthquakes occur in gaps, which have not been ruptured for a long time [McCann et al., 1979]. When a gap is filled by a large earthquake (with meters of slip on the fault plane), the next occurrence is expected to be delayed, since the tectonic stress buildup accumulates at a rate of millimeters to centimeters per year. This elastic rebound theory [Reid, 1910] neglects several important aspects of the earthquake cycle, in particular the fact that gaps can be progressively filled by earthquakes of different magnitudes, which introduces disorder in the repeating times between earthquakes [Ben-Zion and Rice, 1995]. However, when an earthquake occurs with a magnitude corresponding to several hundreds of years of stress accumulation, the elastic rebound theory appears to be empirically verified. In other words, we do not have evidence of a long fault segment ruptured by a major earthquake that breaks again several years after.

On 4 August 2003, a shallow large earthquake (moment magnitude $M_{w}$ 7.6) occurred on the southern boundary of the Scotia plate (Figure 1). This boundary has a complex structure, inherited from the formation of the Scotia plate itself, when the Drake Passage (between Antarctica and South America) opened and resulted in the dispersal of continental fragments of the past Pacific margin along the Scotia Sea periphery [Pelayo and Wiens, 1989; Barker, 2001]. At the longitude of the 2003 earthquake, the Scotia plate is in contact with the South Orkney microcontinent (mostly submerged), and the boundary therefore delimits two domains of different nature and tectonic histories. As expected from the relative movements between Scotia and Antarctica plates (8-9 mm/yr) [Thomas et al., 2003; Smalley et al., 2007], the earthquake mechanism corresponds to a left-lateral movement on a $100^{\circ} \mathrm{N}$ striking fault. In contrast with most large strike-slip earthquakes, the causative fault is not vertical but dips about $45^{\circ}$ to the south. This south dipping character, possibly related to past structures of the South Orkney microcontinent, is in agreement with reflection profiles [Lodolo et al., 2010; Civile et al., 2012].

Ten years later, on 17 November 2013, a slightly larger earthquake $\left(M_{w} 7.8\right)$, with similar focal mechanism and depth, initiated $160 \mathrm{~km}$ west from the epicenter of the 2003 earthquake. Such pairs of large earthquakes with short delay along plate boundaries are not unusual [e.g., Stein et al., 1997; Kagan and Jackson, 1999], and based on the concept of earthquake gaps, the 2013 earthquake should have stopped at the western limit of the 2003 earthquake. However, the spatial distribution of the early aftershocks of both earthquakes contradicts this natural hypothesis (Figures 1 and S1 of the supporting information). In Figure 1, aftershocks have been relocated by simultaneously determining hypocenter locations and station corrections related to errors in the 1-D global velocity model [see Kennett et al., 1995, Text S1 in the supporting information]. The resulting image indicates a narrow east-west rupture zone for both the 2003 and the 2013 


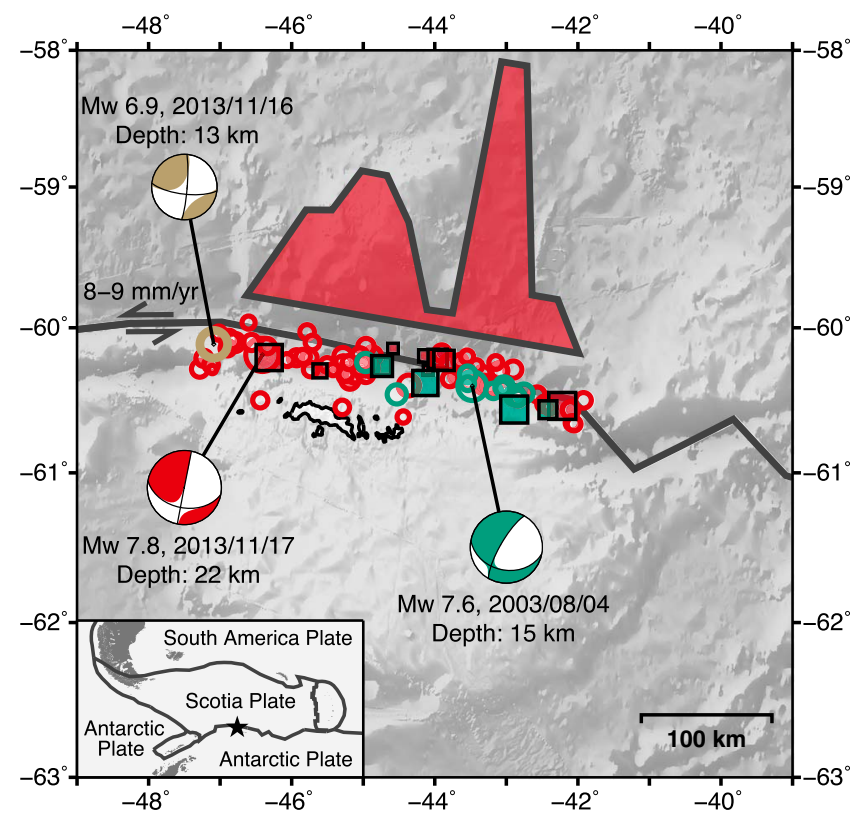

Figure 1. Spatial characteristics of the 2003 and 2013 Scotia Sea earthquakes. Relocated aftershocks for the first 10 days (circles, with size proportional to magnitude) and high-frequency $(0.5-1.0 \mathrm{~Hz})$ radiation sources of the main shock (squares, with size proportional to beam power) are shown with green and red colors for the 2003 and 2013 earthquakes, respectively. Relocated foreshock of 16 November 2013 is indicated by the gold circle. The black thick line shows the boundary between Scotia and Antarctic plates [Bird, 2003]. The slip profile of the 2013 earthquake, determined by the line source modeling (Figure 4), is filled with red. Maximum slip is about $8 \mathrm{~m}$ if assuming a rupture width of $30 \mathrm{~km}$ and a typical rigidity of $3 \cdot 10^{10} \mathrm{~N} \mathrm{~m}^{-2}$. Focal mechanism, magnitude, and centroid depth of the two main shocks and of the foreshock are from the Global Centroid Moment Tensor (GCMT) project [Ekström et al., 2012].

events, and the fault segment affected by the 2003 earthquake appears to have been fully reactivated by the 2013 earthquake.

\section{Source Characteristics of the 2003 and 2013 Scotia Sea Earthquakes}

In order to further explore the puzzling observation of overlapping aftershocks, we used two complementary approaches to analyze the seismic radiation generated by the 2003 and 2013 earthquakes. The first one determines the spatiotemporal history of the high-frequency (HF) source emissions, based on the relative arrival times at a distant seismic array [Ishii et al., 2005; Satriano et al., 2012]. The second one studies the azimuthal variations of the broadband radiation at the global scale, in order to determine how fault slip is distributed along the plate boundary [Nabelek, 1985; Vallée, 2007]. Details of these techniques are provided in Texts $\mathrm{S} 2$ and $\mathrm{S} 3$ in the supporting information.

$\mathrm{HF}$ imaging uses the vertical components of the $P$ body waves, recorded by broadband stations in Central and Southern America (Figures $2 \mathrm{~b}$ and $2 \mathrm{~d}$ ). Velocity signals are filtered between 0.5 and $1.0 \mathrm{~Hz}$, backprojected and stacked at the epicentral region. Peaks in the spatiotemporal distribution of backprojection (BP) stack power indicate the presence of strong HF emitters. The distribution of BP peaks, for the 2003 and 2013 events, with size proportional to the relative BP stack power, is superimposed to the aftershocks in Figure 1. Figures $2 \mathrm{a}$ and $2 \mathrm{c}$ complement this spatial information with the activation time after the event origin and show the trace alignment corresponding to the strongest BP peaks. Figures S2-S5 provide further details on spatiotemporal resolution and peak extraction. The BP analysis supports the image provided by aftershocks: HF emissions, for the late part of the 2013 earthquake (60-90 s), overlap with the HF emissions of the 2003 earthquake. BP analysis also documents the early stage of the 2013 earthquake. During the first 10-15 s (Figures 2c and S3), rupture is little energetic and remains very close to the hypocentral location. This initial phase is easier to interpret in terms of rupture initiation than in terms of foreshock because continuous seismic energy release is observed (Figure S3).

The fault slip determination is based on the analysis of the worldwide broadband stations shown in Figure 3a. Figure $3 \mathrm{~b}$ presents the $P$ wave apparent source time functions (ASTFs) at these stations, obtained 
(a)

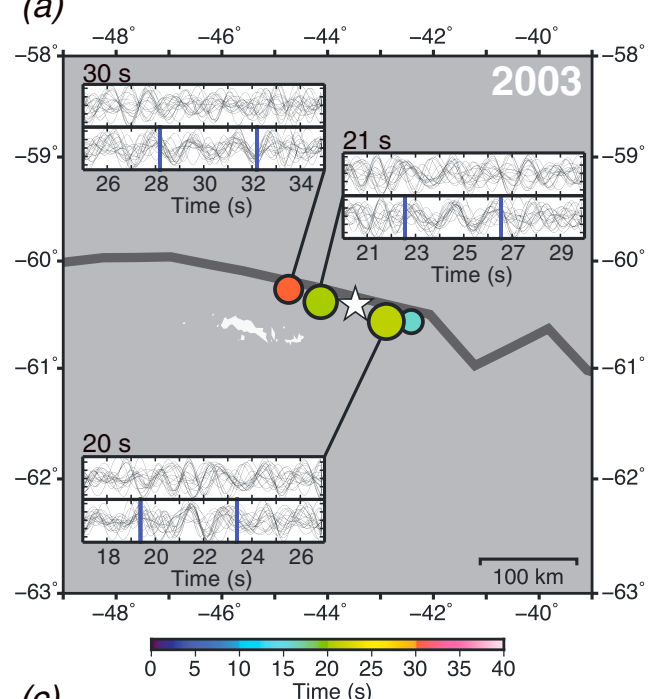

(c)

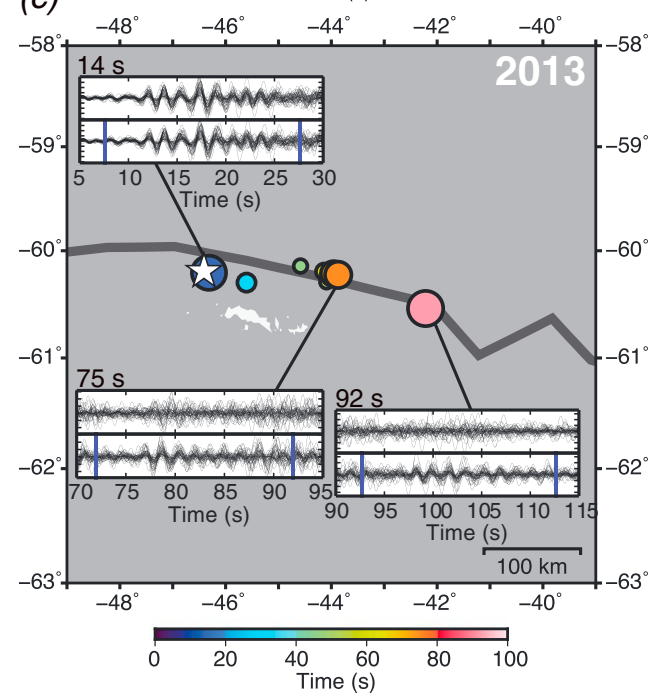

(b)

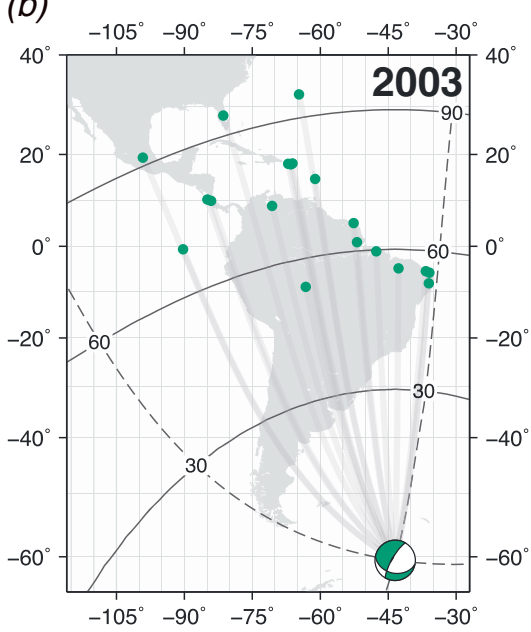

(d)

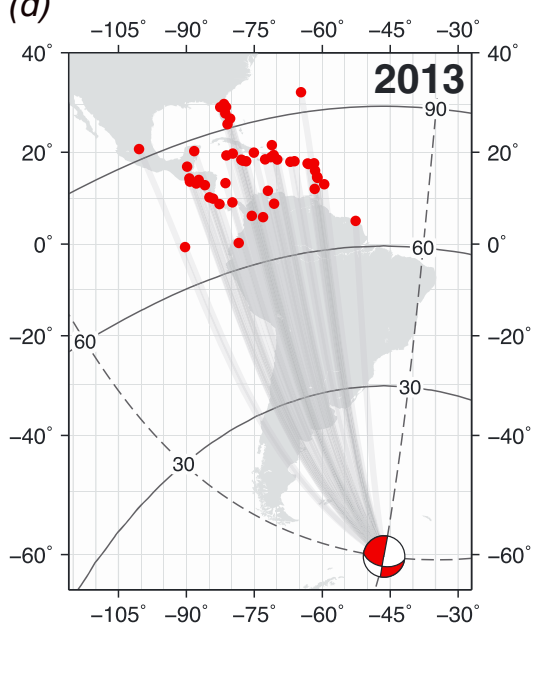

Figure 2. High-frequency analysis of the 2003 and 2013 earthquakes. (a) Strongest radiation sources for the 2003 earthquake from backprojection (BP) analysis. Symbol size is proportional to BP beam power; symbol color represents elapsed time from earthquake origin. The star is the epicenter. Inset plots are three examples of trace alignment at increasing time from earthquake origin (indicated in the upper left): upper plots are seismograms aligned with respect to earthquake origin time and epicentral location; lower plots are time-shifted seismograms with respect to the optimal radiation source location, shown by the corresponding point on the map. (b) Map of the regional stations used for the backprojection analysis (colored dots). Labeled circles show epicentral distances, in degrees. (c and d) Same as Figures $2 a$ and $2 \mathrm{~b}$ for the 2013 earthquake.

after extraction of the Earth response from the seismic signals with the SCARDEC method [Vallée et al., 2011]. These broadband ASTFs are consistent with the earthquake duration determined by backprojection analysis (90-100 s) and show a clear azimuthal dependency: they are stretched when approaching the west direction and more compact in the east direction. This behavior is even more pronounced for ASTFs obtained from $\mathrm{SH}$ waves (Figure S6), as expected from their slower wave velocities. The azimuthal dependency confirms the eastward rupture propagation and can be more specifically analyzed to reconstruct the earthquake slip in terms of line source [Nabelek, 1985; Vallée, 2007, Text S3 in the supporting information]. The corresponding slip profile, shown in Figure 1, is based on the joint modeling of smoothed $P$ wave and $S H$ wave ASTFs (Figure 4). After the initiation phase, lasting 10-15 s, rupture velocity is found around $2.8 \mathrm{~km} / \mathrm{s}$ along the first $100 \mathrm{~km}$ of the eastward earthquake propagation (consistent with BP analysis, see Figure S3) and slows down to values close to $2 \mathrm{~km} / \mathrm{s}$ in the remaining part of the rupture. 
(a)

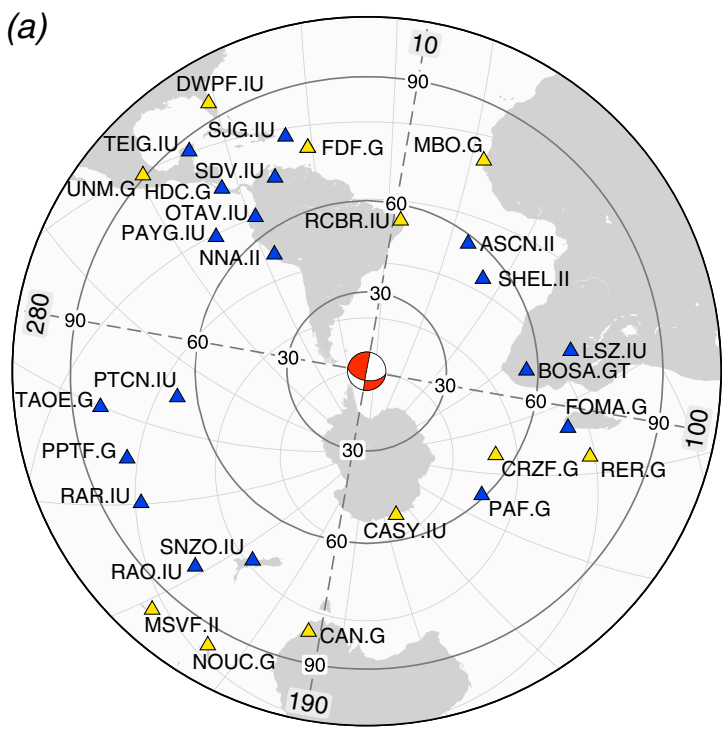

(b)

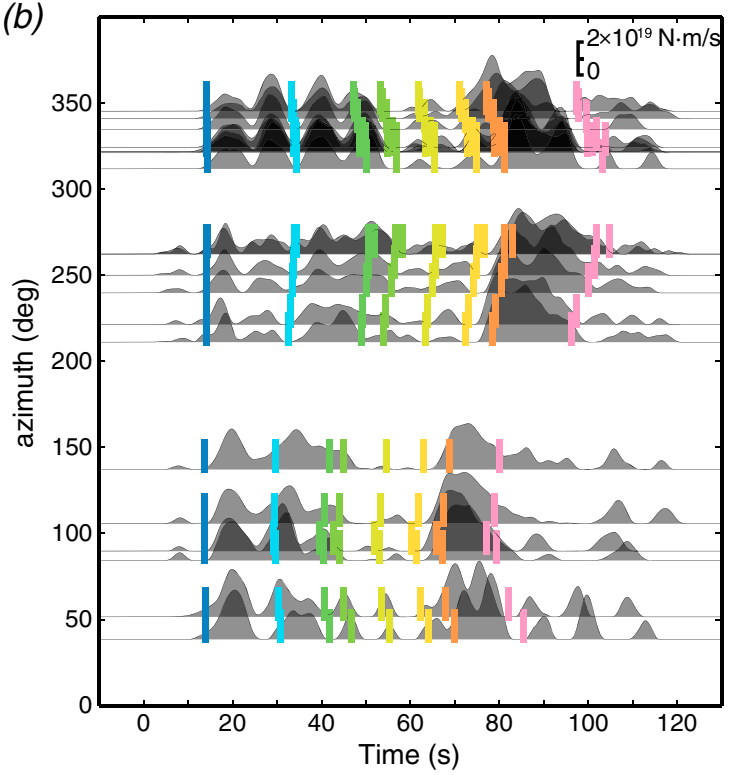

Figure 3. Apparent source time functions (ASTFs) of the 2013 earthquake from $P$ wave analysis (SCARDEC method). (a) Map of the worldwide broadband stations used for the determination of $P$ wave ASTFs (blue triangles). Yellow triangles show stations used in the determination of SH wave ASTFs, included in the line source modeling (Figure 4). Labeled concentric circles show epicentral distances (in degrees) and azimuthal directions (in degrees to the north) are written along the outer circle. (b) $P$ wave ASTFs as a function of azimuth. Eastward propagation is clear from the time differences between moment release episodes, which are larger in the west direction ( $200-360^{\circ}$ azimuth) than in the east direction ( $\sim 45-150^{\circ}$ azimuth). The apparent times, corresponding to the high-frequency locations and timings shown in Figure $2 c$, are shown with the same color scale as in Figure $2 c$. They are in good correlation with abrupt changes of the moment rate functions, corresponding to starting and stopping phases.

The good agreement between modeled and synthetic ASTFs for $P$ and $S H$ waves also indicates that the focal mechanism is fairly stable during earthquake propagation: rupture traveled for about $240 \mathrm{~km}$ with a left-lateral mechanism on a $45-50^{\circ}$ south dipping fault. Although uncommon for large strike-slip earthquakes, this dipping character is mechanically plausible in terms of earthquake initiation. There is no incompatibility between a strike-slip regime (with horizontal maximum and minimum principal stresses and vertical intermediate principal stress) and horizontal motion of a $45-50^{\circ}$ dipping fault. This can be derived from 3-D Mohr circle considerations and has been illustrated by several studies [e.g., Célérier, 1995, Pascal and Angelier, Figure 3c, 2003]: there always exists a particular orientation of principal stresses (with respect to fault strike) which leads to horizontal shear stress and favors strike-slip movement, regardless of the relative magnitudes of the principal stresses. Understanding the persistence of the strike-slip character, along this $240 \mathrm{~km}$ long dipping fault, requires 3-D dynamic simulations that include free surface effects. This kind of analyses has been done on specific examples [Nielsen, 1998; Oglesby et al., 2000], but the case of strike-slip ruptures on dipping faults with a very long aspect ratio does not appear to have been explored till now. The observation of the 2013 Scotia earthquake, together with the recent 2013 Balochistan (Pakistan) earthquake [Avouac et al., 2014], should stimulate further studies in this direction.

Both temporally and spatially, the 2013 earthquake exhibits two main episodes of seismic slip, separated by a $50 \mathrm{~km}$ long low-slip zone. Slip distribution and HF emission depict a very consistent image of the 2013 earthquake. HF emissions are located at the borders of the main slip patches, as it can be seen in Figure 1. In Figures $3 \mathrm{~b}$ and S6, the apparent times of the HF emissions are superimposed on the ASTFs and agree very well with the starting and stopping phases of the main slip episodes. These phases are known to generate localized and impulsive HF radiations [Madariaga, 1977; Campillo, 1983; Sato, 1994], explaining their detections with backprojection techniques.

The epicenter and the aftershocks of the 2003 earthquake are located in the second slip zone of the 2013 earthquake. Observation of the ASTFs of the 2003 earthquake does not show clear dependence with azimuth (Figure S7), indicating a bilateral rupture propagation, in agreement with aftershocks, backprojection imaging, and close locations of the 2003 centroid and hypocenter (closer than $15 \mathrm{~km}$ in the east-west direction, according to the Global Centroid Moment Tensor (GCMT) catalog [Ekström et al., 2012]). Details of the ASTFs of the 2003 earthquake, in particular the late pulse observed in western and northwestern 

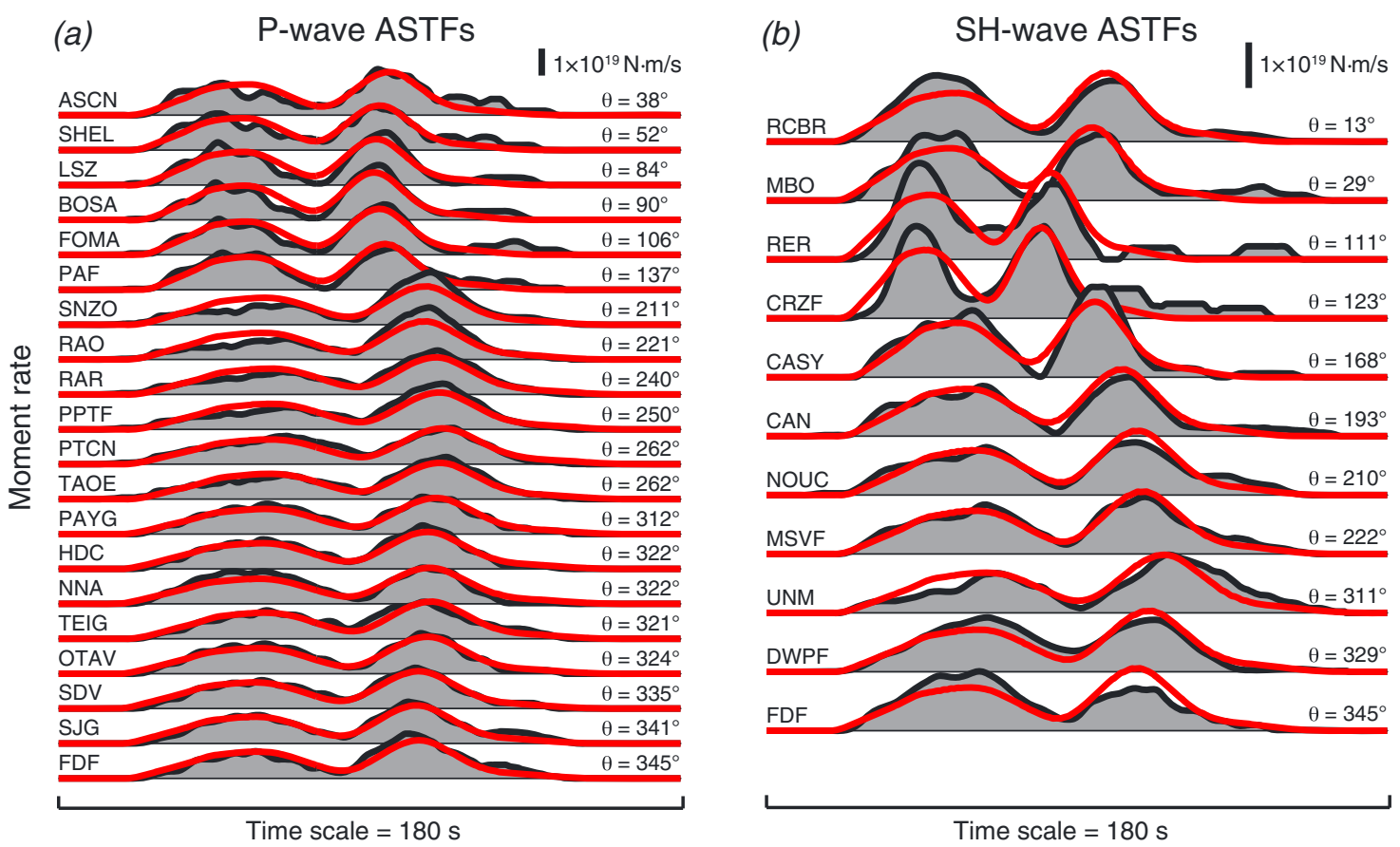

Figure 4. Agreement between observed and synthetic apparent source time functions (ASTFs), for the line source modeling of the 2013 earthquake. (a) $P$ wave teleseismic ASTFs: the observed and modeled ASTFs are grey filled and red, respectively. Name and azimuth $(\Theta)$ of each station are indicated. (b) Same as Figure 4a for the SH wave teleseismic ASTFs. The locations of stations used for $P$ wave and SH wave ASTFs are shown in Figure 3a with blue and yellow triangles, respectively. The moment rate scale is shown at the top of each subfigure. Observed and synthetic ASTFs have been smoothed with azimuth-dependent values (see Text S3 in the supporting information): smoothing values range from $\sim 10 \mathrm{~s}$ for the most directive stations to $\sim 20 \mathrm{~s}$ for the most antidirective stations. The unilateral east rupture propagation, corresponding to the slip profile shown in Figure 1, well models the directivity effects for both $P$ and $S H$ waves.

azimuths (Figure S7), indicate some complexity of the mechanism. However, the dominant mechanism is consistently found similar to the 2013 earthquake by GCMT, SCARDEC [Vallée et al., 2011], and W phase methods (T. Lay, personal communication, 2014). In the $100 \mathrm{~km}$ long segment located between $42.3^{\circ} \mathrm{W}$ and $44^{\circ} \mathrm{W}$, both earthquakes released similar seismic moment (equivalent to moment magnitude 7.6 ), in the same amount of time (30 s, Figures 2 and S7). Along dip, a full differentiation in depth would require very thin rupture zones (a few kilometers wide), since the centroids of both earthquakes are similar and shallow $(<25 \mathrm{~km}$, Figure 1). This seems an unrealistic hypothesis for such large earthquakes $(M>7.5)$. All these elements converge toward the repeated activation of the western segment by two large earthquakes-with meters of fault slip-separated by only 10 years.

Given the structural complexity of the area and the internal complexity of the 2003 earthquake, it cannot be excluded that the two events occurred on different strands of the same western segment. If separated by less than a few tenths of kilometers, these strands cannot be revealed by the teleseismic methods applied here. Even accepting this hypothesis, the occurrence of the 2013 earthquake remains puzzling, since the 2003 earthquake reduced the shear strain available for future strike-slip earthquakes not only on its fault plane but also within the surrounding volume.

\section{Discussion and Implications}

Previous observations of overlapping rupture segments along strike-slip faults involve pairs of smaller earthquakes: the $1940\left(M_{w} 7.1\right)$ and $1979\left(M_{w} 6.6\right)$ Imperial Valley earthquakes [King and Thatcher, 1998; Rockwell and Klinger, 2013], the $1981\left(M_{w} 7.1\right)$ and $1998\left(M_{w} 6.6\right)$ Gowk fault (Iran) earthquakes [Berberian et al., 2001], and the $1979\left(M_{w} 6.6\right)$ and $1997\left(M_{w} 7.2\right)$ Zirkuh (Iran) earthquakes [Berberian et al., 1999]. In the 1939-1999 sequence along the North Anatolian fault, overlaps between earthquakes also exist [Barka, 1996]. In these examples, the repeated slip could be explained by stress readjustments at places that did not slip enough during the previous event (similar to a foreshock-main shock-aftershock sequence). Moreover, the case of the Imperial Valley sequence, and of another earthquake pair in the Japan subduction zone (1978 and 2005 Miyagi-Oki earthquakes), could be simply understood by the stress buildup during the interevent time [King and Thatcher, 1998; Wu et al., 2008]. In contrast with these previous observations, based on their magnitude, 
both Scotia earthquakes are believed to mark the end of a long interseismic period, and their interevent time is much too short to allow significant stress buildup.

How such a short time interval between two major earthquakes on the same fault segment can be interpreted? A key element likely resides in the location of the hypocenter of the 2013 earthquake, which occurred outside the zone affected by the 2003 earthquake (Figure 1). In this area, initiation was promoted and the 2013 earthquake rapidly propagated eastward. The west direction was less favorable because of the foreshock occurring the day before $\left(M_{w} 6.9\right.$, Figure 1). When arriving in the zone that has been ruptured in 2003, both slip and rupture velocity decreased due to the reduction of the tectonic stresses [Das and Aki, 1977], or due to friction properties changes from velocity weakening to velocity strengthening [Kaneko et al., 2010]. In the case of velocity strengthening, this modification of the friction law would have also caused the end of the westward propagation of the 2003 earthquake. Such a rupture deceleration increases the shear stresses created by the earthquake itself at and ahead of the rupture front [Das and Aki, 1977; Kaneko et al., 2010; Shibazaki and Matsu'ura, 1992], favoring rupture reactivation.

Within its rupture zone, the 2003 earthquake reorganized the stresses, with a global trend of reducing them. However, the slip distribution heterogeneities also create some areas of slight stress drops or even local stress increases. This does not require that the 2003 earthquake left some large unbroken regions, which would not be consistent with the magnitude-size scaling for such a large strike-slip earthquake [Wells and Coppersmith, 1994], but only that some areas slipped less than others. Inside these specific areas, the dynamic stresses induced by the first episode of the 2013 earthquake may have been sufficient to nucleate a secondary rupture [Zhang et al., 2012], which further propagated eastward (Figures 2 and S3). The magnitude of this second episode $\left(M_{w} 7.6\right.$, similar to the 2003 earthquake) implies that the 2013 earthquake ruptured large zones that have been unloaded by the 2003 earthquake. This behavior can be understood if the dynamic stress increase at the rupture front is much larger than the static stress drop induced by past events, as proposed by Heaton [1990].

The existence of clustered and colocated large earthquakes has been supported by paleoseismological studies [Schlagenhauf et al., 2011, and references therein]. For example, the time difference between the 1812 and 1857 large Californian earthquakes is much shorter than the average recurrence [Jacoby et al., 1988]. The Scotia pair is a first instrumental evidence of this behavior, with an interevent time so short that it would likely have been considered as the same event by paleoseismological analyses. Regardless of the

Acknowledgments

We are grateful to broadband seismic network operators (IU, G, II, and GT networks at the global scale and $\mathrm{BL}$, $\mathrm{CM}, \mathrm{CN}, \mathrm{CU}, \mathrm{CY}, \mathrm{DR}, \mathrm{G}, \mathrm{GI}, \mathrm{II}, \mathrm{IU}, \mathrm{JM}$, $M G, N A, N U, P A, P R, S V, T A$, and WI networks in Central and South America), for high-quality data and public access to continuous waveforms. Data have been retrieved through IRIS (www. iris.edu) and GEOSCOPE (geoscope. ipgp.fr) websites. Several calculations used the S-CAPAD cluster of Institut de Physique du Globe de Paris. We thank the ALEAS program of INSU and the NERA european project for their support. Part of data analysis has been carried out using ObsPy [Megies et al., 2011]. Figures have been realized using GMT5 [Wessel et al., 2013] and Matplotlib [Hunter, 2007]. We thank Thorne Lay and an anonymous reviewer for their comments, which helped to improve the manuscript. This study has benefited from interactive discussions with Pascal Bernard. Information provided by Harsha Bhat and Yann Klinger (on 3-D Mohr circle and past examples of earthquake recurrence) was very helpful.

The Editor thanks Thorne Lay and an anonymous reviewer for their assistance in evaluating this paper. fault mechanics explaining such a clustered earthquake pair, its observation has direct consequences for seismic hazard assessment. Even if an earthquake, close to the maximum size that a fault system is believed to generate, has recently occurred on a fault segment, this segment should not be considered safe from similar ruptures in the near future. Such a repeated sequence can be favored by the existence of a contiguous seismic gap, in which a successive rupture can nucleate and propagate toward the previous earthquake.

\section{References}

Avouac, J.-P., F. Ayoub, S. Wei, J. P. Ampuero, L. Meng, S. Leprince, R. Jolivet, Z. Duputel, and D. Helmberger (2014), The 2013, Mw 7.7 Balochistan earthquake, energetic strike-slip reactivation of a thrust fault, Earth Planet. Sci. Lett., 391, 128-134, doi:10.1016/j.epsl.2014.01.036.

Barka, A. (1996), Slip distribution along the North Anatolian fault associated with the large earthquakes of the period 1939 to 1967, Bull. Seismol. Soc. Am., 86(5), 1238-1254.

Barker, P. F. (2001), Scotia Sea regional tectonic evolution: Implications for mantle flow and palaeocirculation, Earth Sci. Rev., 55(1-2), 1-39, doi:10.1016/S0012-8252(01)00055-1.

Ben-Zion, Y., and J. R. Rice (1995), Slip patterns and earthquake populations along different classes of faults in elastic solids, J. Geophys. Res., 100, 12,959-12,983, doi:10.1029/94JB03037.

Berberian, M., J. A. Jackson, M. Qorashi, M. M. Khatib, K. Priestley, M. Talebian, and M. Ghafuri-Ashtiani (1999), The 10 May 1997 Zirkuh (Qa'enat) earthquake (Mw 7.2): Faulting along the Sistan suture zone of eastern Iran, Geophys. J. Int., 136, 671-694, doi:10.1046/j.1365-246x.1999.00762.x.

Berberian, M., C. Baker, E. Fielding, J. A. Jackson, B. E. Parsons, K. Priestley, M. Qorashi, M. Talebian, R. Walker, and T. J. Wright (2001), The 14 March 1998 Fandoqa earthquake (Mw 6.6) in Kerman province, S. E. Iran: Re-rupture of the 1981 Sirch earthquake fault, triggering of slip on adjacent thrusts and the active tectonics of the Gowk fault zone, Geophys. J. Int., 146, 371-398, doi:10.1046/j.1365-246x.2001.01459.x.

Bird, P. (2003), An updated digital model of plate boundaries, Geochem. Geophys. Geosyst., 4(3), 1027, doi:10.1029/2001GC000252.

Campillo, M. (1983), Numerical evaluation of the near-field high-frequency radiation from quasi-dynamic circular faults, Bull. Seismol. Soc. Am., 73, 723-734

Célérier, B. (1995), Tectonic regime and slip orientation of reactivated faults, Geophys. J. Int., 121 (1), 143-161, doi:10.1111/j.1365-246X.1995.tb03517.x.

Civile, D., E. Lodolo, A. Vuan, and M. F. Loreto (2012), Tectonics of the Scotia-Antarctica plate boundary constrained from seismic and seismological data, Tectonophysics, 550-553, 17-34, doi:10.1016/j.tecto.2012.05.002. 
Das, S., and K. Aki (1977), Fault plane with barriers: A versatile earthquake model, J. Geophys. Res., 82, 5658-5670, doi:10.1029/JB082i036p05658.

Ekström, G., M. Nettles, and A. M. Dziewonski (2012), The global CMT project 2004-2010: Centroid-moment tensors for 13,017 earthquakes, Phys. Earth Planet. Inter., 200-201, 1-9, doi:10.1016/j.pepi.2012.04.002.

Heaton, T. H. (1990), Evidence for and implications of self-healing pulses of slip in earthquake rupture, Phys. Earth Planet. Inter., 64, 1-20, doi:10.1016/0031-9201(90)90002-F.

Hunter, J. D. (2007), Matplotlib: A 2D graphics environment, Comput. Sci. Eng., 9(3), 90-95, doi:10.1109/MCSE.2007.55.

Ishii, M., P. M. Shearer, H. Houston, and J. E. Vidale (2005), Extent, duration and speed of the 2004 Sumatra-Andaman earthquake imaged by the Hi-Net array, Nature, 435, 933-936, doi:10.1038/nature03675.

Jacoby, G., P. Sheppard, and K. Sieh (1988), Irregular recurrence of large earthquakes along the San Andreas Fault in southern California-Evidence from trees near Wrightwood, Science, 241, 196-199, doi:10.1126/science.241.4862.196.

Kagan, Y. Y., and D. D. Jackson (1999), Worldwide doublets of large shallow earthquakes, Bull. Seismol. Soc. Am., 89, $1147-1155$.

Kaneko, Y., J.-P. Avouac, and N. Lapusta (2010), Towards inferring earthquake patterns from geodetic observations of interseismic coupling, Nat. Geosci., 3, 363-369, doi:10.1038/ngeo843.

Kennett, B., E. R. Engdahl, and R. Buland (1995), Constraints on seismic velocities in the Earth from traveltimes, Geophys. J. Int., 122, 108-124, doi:10.1111/j.1365-246X.1995.tb03540.x.

King, N. E., and W. R. Thatcher (1998), The coseismic slip distribution of the 1940 and 1979 Imperial Valley, California, earthquakes and their implications, J. Geophys. Res., 103, 18,069-18,086, doi:10.1029/98JB00575.

Lodolo, E., D. Civile, A. Vuan, A. Tassone, and R. Geletti (2010), The Scotia Antarctica plate boundary from $35^{\circ} \mathrm{W}$ to $45^{\circ} \mathrm{W}$, Earth Planet. Sci. Lett., 293, 200-215, doi:10.1016/j.epsl.2009.12.045.

Madariaga, R. (1977), High-frequency radiation from crack (stress drop) models of earthquake faulting, Geophys. J. R. Astron. Soc., 51, 625-651, doi:10.1111/j.1365-246X.1977.tb04211.x.

McCann, W. R., S. P. Nishenko, L. R. Sykes, and J. Krause (1979), Seismic gaps and plate tectonics: Seismic potential for major boundaries, Pure Appl. Geophys., 117, 1082-1147, doi:10.1007/BF00876211.

Megies, T., M. Beyreuther, R. Barsch, L. Krischer, and J. Wassermann (2011), ObsPy-What can it do for data centers and observatories?, Ann. Geophys., 54(1), 47-58, doi:10.4401/ag-4838.

Nabelek, J. (1985), Geometry and mechanism of faulting of the 1980 El-Asnam, Algeria, earthquake from inversion of teleseismic body waves and comparison with field observations, J. Geophys. Res., 90, 2713-2728, doi:10.1029/JB090iB14p12713.

Nielsen, S. B. (1998), Free surface effects on the propagation of dynamic rupture, Geophys. Res. Lett., 25(1), 125-128, doi:10.1029/97GL03445.

Oglesby, D. D., R. J. Archuleta, and S. B. Nielsen (2000), The three-dimensional dynamics of dipping faults, Bull. Seismol. Soc. Am., 90(3), 616-628, doi:10.1785/0119990113.

Pascal, C., and J. Angelier (2003), SORTAN: An analytical method to determine fault slip as induced by stress, Math. Geol., 35(5), 627-642, doi:10.1023/A:1026238819760.

Pelayo, A. M., and D. A. Wiens (1989), Seismotectonics and relative plate motions in the Scotia Sea region, J. Geophys. Res., 94, 7293-7320, doi:10.1029/JB094iB06p07293.

Reid, H. F. (1910), The California Earthquake of April 18, 1906, Carnegie Institution of Washington, Washington, D. C.

Rockwell, K. T., and Y. Klinger (2013), Surface rupture and slip distribution of the 1940 Imperial Valley earthquake, Imperial fault, southern California: Implications for rupture segmentation and dynamics, Bull. Seismol. Soc. Am., 103, 629-640, doi:10.1785/0120120192.

Sato, T. (1994), Seismic radiation from circular cracks growing at variable rupture velocity, Bull. Seismol. Soc. Am., 84, $1199-1215$.

Satriano, C., E. Kiraly, P. Bernard, and J.-P. Vilotte (2012), The 2012 Mw 8.6 Sumatra earthquake: Evidence of westward sequential seismic ruptures associated to the reactivation of a N-S ocean fabric, Geophys. Res. Lett., 39, L15302, doi:10.1029/2012GL052387.

Schlagenhauf, A., I. Manighetti, L. Benedetti, Y. Gaudemer, R. Finkel, J. Malavieille, and K. Pou (2011), Earthquake supercycles in Central Italy, inferred from $36 \mathrm{Cl}$ exposure dating, Earth Planet. Sci. Lett., 307, 487-500, doi:10.1016/j.epsl.2011.05.022.

Shibazaki, B., and M. Matsu'ura (1992), Spontaneous processes for nucleation, dynamic propagation, and stop of earthquake rupture, Geophys. Res. Lett., 19, 1189-1192, doi:10.1029/92GL01072.

Smalley, R. Jr., I. W. D. Dalziel, M. G. Bevis, E. Kendrick, D. S. Stamps, E. C. King, F. W. Taylor, E. Lauría, A. Zakrajsek, and H. Parra (2007), Scotia arc kinematics from GPS geodesy, Geophys. Res. Lett., 34, L21308, doi:10.1029/2007GL031699.

Stein, R. S., A. A. Barka, and J. H. Dieterich (1997), Progressive failure on the North Anatolian fault since 1939 by earthquake stress triggering, Geophys. J. Int., 128, 594-604, doi:10.1111/j.1365-246X.1997.tb05321.x.

Thomas, C., R. Livermore, and F. Pollitz (2003), Motion of the Scotia Sea plates, Geophys. J. Int., 155, 789-804, doi:10.1111/j.1365-246X.2003.02069.x.

Vallée, M. (2007), Rupture properties of the giant Sumatra earthquake imaged by empirical Green function analysis, Bull. Seismol. Soc. Am., 97(1A), S103-S114, doi:10.1785/0120050616.

Vallée, M., J. Charléty, A. M. G. Ferreira, B. Delouis, and J. Vergoz (2011), SCARDEC: A new technique for the rapid determination of seismic moment magnitude, focal mechanism and source time functions for large earthquakes using body wave deconvolution, Geophys. J. Int., 184, 338-358, doi:10.1111/j.1365-246X.2010.04836.x.

Wells, D. L., and J. C. Coppersmith (1994), New empirical relationships among magnitude, rupture length, rupture width, rupture area and surface displacement, Bull. Seismol. Soc. Am., 84, 974-1002.

Wessel, P., W. H. F. Smith, R. Scharroo, J. Luis, and F. Wobbe (2013), Generic mapping tools: Improved version released, EOS Trans. Am. Geophys. Union, 94(45), 409-410, doi:10.1002/2013EO450001.

Wu, C., K. Koketsu, and H. Miyake (2008), Source processes of the 1978 and 2005 Miyagi-oki, Japan, earthquakes: Repeated rupture of asperities over successive large earthquakes, J. Geophys. Res., 113, B08316, doi:10.1029/2007JB005189.

Zhang, G., M. Vallée, X. Shan, and B. Delouis (2012), Evidence of sudden rupture of a large asperity during the 2008 Mw7.9 Wenchuan earthquake based on strong motion analysis, Geophys. Res. Lett., 39, L17303, doi:10.1029/2012GL052516. 